\title{
SÔBRE UM NÔVO GÊNERO DA SUBFAMILIA DICHEILONEMATINAE WEHR, 1935 (Nematoda, Filarioidea) *
}

\section{H. DE OLIVEIRA RODRIGUES E SERGIO RAYMUNDO NEGRÃO DE SOUZA FRANCO}

Instituto Oswaldo Cruz, Rio de Janeiro, Guanabara

\author{
Instituto Evandro Chagas, \\ Belém, Pará
}

(Com 5 figuras no texto)

Em autópsia de um espécime de Tyto alba tuidara (Gray), realizada na Seção de Helmintologia do Instituto Oswaldo Cruz, em março de 1963, encontramos, na cavidade geral, dois nematódeos filarídeos machos, da subfamília Dicheilonematinae Wehr, 1935.

Depois de rever a bibliografia referente aos gêneros conhecidos da subfamília, concluímos tratar-se de um gênero ainda não descrito, o que fazemos no presente trabalho.

Propomos o nome Tytofilaria para o nôvo gênero e, em homenagem ao Professor Paulo Friedrich Bührnheim, que gentilmente nos ofereceu o animal para ser necropsiado, denominamos a espécie Tytofilaria pauloi $\mathrm{sp}$. $\mathrm{n}$.

Tytofilaria gen. $n$.

Dicheilonematinae. Bôca provida de dois lábios laterais em forma de tronco de cone. Espessamentos cuticulares cefálicos laterais presentes, com 6 grandes papilas: duas ventrais, duas dorsais e um par lateral. Esôfago longo, apresentando duas porções: uma anterior, curta e delgada, e uma posterior, longa e dilatada. Machos com cauda curta, arredondada, provida de duas asas laterais que terminam antes da extremidade posterior; papilas pedunculadas grandes e papilas sésseis pósanais presentes; espículos desiguais, não alados, um longo e delgado

* Recebido para publicação a 17 de junho de 1963.

Trabalho do Instituto Oswaldo Cruz (Divisão de Zoologia) e do Instituto Evandro Chagas, realizado com o auxílio do Conselho Nacional de Pesquisas e da Superintendência do Plano de Valorização Econômica da Amazônia (S.P.V.E.A.). 
e outro curto e grosso; a relação entre êles, variando em tôrno de $1: 5$ a 1:6; gubernáculo ausente. Fêmeas desconhecidas. Parasitos de aves. Espécie tipo - T. pauloi sp. $n$.

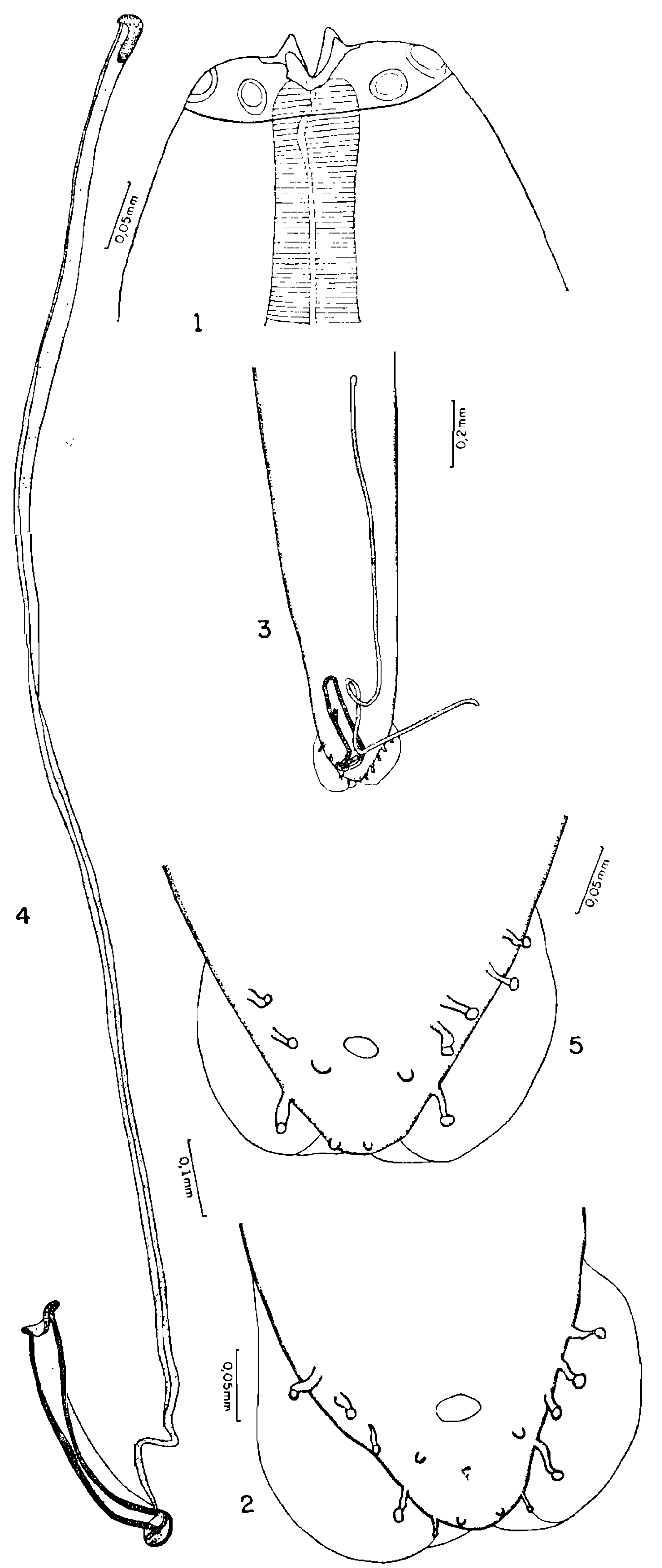

Tytofilaria pauloi gen. n., sp. n. - Fig. 1: Extremidade cefálica do parátipo, vista ventral; flg. 2: extremidade caudal do holótipo, vista ventral; fig. 3: extremidade posterior do holótipo, vista ventral; fig. 4: espículos do parátipo; fig. 5: extremidade caudal do parátipo, vista ventral. 
Tytofilaria pauloi sp. $\mathrm{n}$.

Corpo alongado, filiforme, medindo 41,1 a $52,5 \mathrm{~mm}$ de comprimento por 0,63 a $0,64 \mathrm{~mm}$ de largura máxima, com cutícula branca, estriada transversal e longitudinalmente. Extremidades afiladas. Bôca provida de dois lábios laterais em forma de tronco de cone, sendo mais quitinizados na sua porção basal. Espessamentos cuticulares cefálicos laterais presentes, com 6 grandes papilas: 1 par ventral, 1 par dorsal e 1 par lateral. O esôfago, bastante longo, com 11,45 a $17,43 \mathrm{~mm}$ de comprimento, é constituído de duas porções, sendo a anterior bem mais curta e delgada, medindo $0,381 \mathrm{~mm}$ de comprimento e a posterior longa e dilatada. Anel nervoso situado a 0,125 a $0,198 \mathrm{~mm}$ da extremidade anterior. Extremidade posterior arredondada e com asas caudais que medem 0,182 a 0,199 $\mathrm{mm}$ de comprimento e 0,049 $\mathrm{mm}$ de maior largura. Papilas caudais presentes: 5 pares de papilas pedunculadas, equidistantes (em um dos exemplares encontramos 5 papilas de um lado e 3 do outro) e 2 pares de papilas sésseis pós-anais, um logo depois do ânus e o outro junto da ponta da cauda. Espículos desiguais, não alados, sendo um longo e delgado, medindo 1,87 a $2,27 \mathrm{~mm}$ de comprimento por $0,033 \mathrm{~mm}$ de largura e outro, curto e grosso, com $0,381 \mathrm{~mm}$ de comprimento por $0,049 \mathrm{~mm}$ de largura. O espículo maior apresenta a extremidade proximal um pouco dilatada e a distal ligeiramente recurvada e pontuda; o menor tem a extremidade proximal alargada e a distal romba. Gubernáculo ausente. O ânus dista 0,079 a $0,085 \mathrm{~mm}$ da extremidade posterior.

Habitat - Cavidade geral de Tyto alba tuidara (Gray) .

Proveniência - Manguinhos, Rio de Janeiro, Estado da Guanabara, Brasil.

Holótipo macho n. ${ }^{0} 29.182$ a e parátipo n. ${ }^{\circ} 29.182 \mathrm{~b}$, depositados na Coleção Helmintológica do Instituto Oswaldo Cruz.

\section{DISCUSSÃO}

Na subfamília Dicheilonematinae Wehr, 1935, encontramos os seguintes gêneros: Dicheilonema Diesing, 1861 (sin: Contortospiculum Skrjabin \& Petrov, 1928); Serratospiculum Skrjabin, 1915; Heterospiculum Shigin, 1951; Monopetalonema Diesing, 1861 (sin: Ornithosetaria Sandground, 1933, Politospiculum Skrjabin, 1916) e Pharyngosetaria Lubimov, 1937. O presente gênero diferencia-se de Dicheilonema por apresentar asas caudais não envolvendo o ápice caudal e por ter espículos não alados, sendo o maior longo e fino e o menor curto e grosso; de Hamatospiculum por apresentar asas caudais terminando antes da extremidade posterior, não a envolvendo, por serem as papilas pedunculadas grandes, pela relação entre o comprimento dos espículos que em nosso gênero varia de $1: 5$ a $1: 6$, enquanto que no de SkrJabIN é de $1: 10$, aproximadamente, e por ter o espículo menor bem mais grosso; de Serratospiculum por apresentar asas caudais terminando antes da 
extremidade pasterior, não a envolvendo, pelas papilas pedunculadas muito maiores, pelos espículos não alados e não serreados, e por possuir dois lábios nítidos; de Heterospiculum por apresentar dois lábios nítidos, espículo maior longo e delgado e por ser o espículo menor não alado; de Monopetalonema pelos espessamentos cuticulares cefálicos em tôrno da bôca, pelas asas caudais terminando antes da extremidade posterior, não a envolvendo, e pelo espículo maior desprovido de asa; de Pharyngosetaria pelos espessamentos cuticulares cefálicos laterais em tôrno da bôca, pelas asas caudais presentes e por não possuir cápsula bucal.

\section{REFERENCIAS BIBLIOGRÁFICAS}

Diesing, K. M., 1861, Revision der Nematoden. Sitzungsb. Akad. Wiss. Math. Naturw. Cl, 42 (28): 595-736.

Freitas, J. F. T. \& LENT, H., 1936, O gênero Monopetalonema Diesing, 1861 (Nematoda: Filarioidea). Mem. Inst. Oswaldo Cruz, 31 (4): 747-756, 3 ests., 12 figs.

SkrJabIN, K. I., 1916, Contribution à l'étude de la faune helminthologique du Paraguay. J. Russ. Zool. Petrograd, 1 (4) : 736-757, ests. 24-26, figs. 1-27.

YAMAGUTI, S., 1961, Systema Helminthum, 3, The nematodes of vertebrates, Part. 1: 679 pp., Part. 2: 681-917, 1125-1261, 102 pls., 909 figs., Interscience Publishers, Inc. ed., New York.

YoRke, W. \& MAplestone, P. A., 1926, The Nematodes Parasites of Vertebrates, VII + 536 pp., 307 figs., London. 